\title{
Kotieläinten käyttäytymisen tuntemus on edellytys hyvälle eläintenpidolle: Helsingin yliopiston Eläinten hyvinvoinnin tutkimuskeskus esittäytyy
}

\author{
Anna Valros ${ }^{1)}$, Laura Hänninen ${ }^{1)}$, Satu Raussi ${ }^{2)}$, Helena Hepola ${ }^{3)}$, Marianna Norring ${ }^{1)}$, Matti \\ Heikkilä $^{1)}$, Hannu Saloniemi ${ }^{1)}$ \\ ${ }^{1)}$ Eläinten hyvinvoinnin tutkimuskeskus, Eläinlääketieteellinen tiedekunta, PL 57, 00014 Helsingin \\ yliopisto,anna.valros@helsinki.fi \\ 2) Eläinten hyvinvoinnin tutkimuskeskus, MTT maatalousteknologian tutkimus (Vakola), \\ Vakolantie 55, 03400 Vihti \\ ${ }^{3)}$ Eläinten hyvinvoinnin tutkimuskeskus, Kotieläintieteen laitos, PL 28, 00014 Helsingin yliopisto
}

\section{Johdanto}

Eläinten hyvinvoinnin tutkimuskeskus perustettiin Helsingin yliopistoon syksyllä 2003, vastaamaan yhteiskunnallisiin ja tieteellisiin tarpeisiin. Kotieläintuotannon menetelmät ja tilojen koot ovat viime vuosina muuttuneet nopeasti. Tilakoko suurenee vuosi vuodelta ja tiloja automatisoidaan yhä pidemmälle. Muutokset eivät välttämättä huononna eläinten hyvinvointia, kehitys on monessa tapauksessa ollut positiivista, esimerkkejä tästä ovat pihattoratkaisujen ja lattiakanaloiden yleistyminen. Joissakin tapauksissa kustannustehokkuus viedään kuitenkin niin pitkälle, että eläinten hyvinvointi vaarantuu. Kaikissa tapauksissa muutokset tuovat mukanaan uusia haasteita eläinten hyvinvointitieteelle. Samalla yhteiskunnallinen keskustelu ja eläinten oloista ja hyvinvoinnista on jatkuvasti vilkastunut.

Tieteellinen tutkimus on tarpeen, jotta päättäjille, tuottajille ja suurelle yleisölle voitaisiin tarjota objektiivista tietoa eläinten tarpeista ja hyvinvoinnista. Eläinten hyvinvointitutkimuksen kautta edistetään sekä eläinten hyvinvointia että ratkaistaan tuotannollisia ongelmia. Tärkeätä on myös muistaa, että vaikka tuotos ei yksinään ole luotettava indikaattori hyvinvoinnin tasosta, hyvinvoivat eläimet tuottavat pitkällä tähtäimellä paremmin. Eläinten hyvinvointia tutkittaessa lähdetään perusolettamuksesta, että lajienkehityksen myötä kotieläimemme ovat geneettisesti varustettuja käyttäytymistarpeilla ja kyvyllä selviytyä tiettyyn rajaan asti vaihtelevista tilanteista. Hyvinvointi on suure, joka kuvaa eläimen sopeutumista tuotanto-olosuhteissa.

Eläinten hyvinvointia on tutkittu viimeisen kolmenkymmenen vuoden aikana Euroopassa ja Pohjois-Amerikassa. Pääosin hyvinvointitukimusta on tehty soveltavan käyttäytymistieteen tutkijoiden yhteisössä (ISAE). Suomessa alan tutkimus on kohtuullisen nuorta, n. 15 vuotta vanhaa. Tutkittua ja sovellettavissa olevaa tietoa on jo saatavilla, ja kotimaisista hankkeista on tulossa lisää. HYstä puuttui kuitenkin syksyyn 2003 asti kotieläinten soveltavan käyttäytymistieteen tutkimuksen kokoava ja tuloksista tiedottava foorumi.

\section{Käyttäytymisen avulla voidaan havaita tila- ja käsittelyongelmat ajoissa}

Kotieläinten tuotantoympäristön, hoidon ja käsittelyn suunnitellussa on huomioitava eläinten luontaiset käyttäytymistarpeet, sillä vääränlaisessa ympäristössä eläimen hyvinvointi heikkenee. Ympäristön tulisi myös tarjota eläimelle fysikaalisesti sopivat olosuhteet esimerkiksi lämpötilan, ilmanlaadun ja ruokinnan suhteen. Alhainen hyvinvoinnin taso on itsessään argumentti olosuhteiden tai hoidon parantamiselle mutta hyvinvointi on tärkeä myös taloudellisista näkökulmista. Stressi, erilaiset käyttäytymishäiriöt sekä sairaudet ja vauriot kuluttavat eläimen energiavarastoja ja vähentävät tuotantoon käytettävissä olevaa energiamäärää. Esimerkiksi hännänpurenta alentaa sikojen kasvua, vaikka purennasta aiheutuvat tulehdukset hoidetaan lääkkeillä (Wallgren \& Lindahl, 1996). Varsinkin krooninen stressi alentaa eläimen puolustuskykyä, altistaen eläintä erilaisille taudinaiheuttajille (Toates, 1995). Käyttäytymisen tuntemus on tärkeätä myös tilatason työssä - havaitsemalla pienetkin poikkeavuudet tai muutokset käyttäytymisessä voi eläintenhoitaja korjata tilanteen ennen kuin ongelmat heijastuvat eläimen terveyteen ja tuotokseen. Eläinten käyttäytymisen tunteminen auttaa käsittelemään eläimiä oikein, jolloin voidaan vähentää eläinten pelkoa ja stressiä (Raussi ym, 2003) sekä sitä kautta parantaa työturvallisuutta.

Tuotos yksinään on liian karkea hyvinvoinnin mittari. Terveys vaikuttaa tietenkin suuresti eläimen hyvinvointiin, mutta kun eläin sairastuu tai sen tuotos laskee, on tuottaja jo kärsinyt taloudellisia tappioita. Hyvinvoinnin heikkenemisen merkit ovat todennäköisesti olleet jo pitkään 
näkyvissä. Koska käyttäytymisen muutokset heijastavat eläinten sopeutumismahdollisuuksia elinoloihinsa jo aikaisessa vaiheessa ja herkästi, on käyttäytymisen kautta mahdollista tunnistaa hyvinvoinnin riskitekijät ennen kuin eläin sairastuu tai sen tuotos alenee.

Eläimen evolutiivinen tausta, eli ne luonnonolot, joissa eläin on alun perin kehittynyt, on tärkeää tuntea. Tuotantoeläinten käyttäytyminen ja tarpeet ovat muuttuneet hyvin vähän villeihin sukulaisiin verrattuna. Esimerkiksi kesyemakolla on edelleen sisäsyntyinen pesänrakentamistarve, joka herää ennen porsimista ympäristöstä riippumatta. Hormonaaliset muutokset saavat emakon rakentamispuuhiin. Jos pesänrakentaminen estyy, emakon turhautuminen voidaan havaita käyttäytymismuutoksista: emakko on levottomampi (Damm ym. 2002) ja saattaa jatkaa pesänrakentamista porsimisen aikana (Thodberg ym, 1999). Mitä enemmän pesänrakentamista rajoitetaan, sitä suuremmat ovat negatiiviset vaikutukset: porsiminen pitkittyy eivätkä emakon emovaistot kehity luontaisen voimakkaiksi (Herskin ym, 1998, Thodberg ym, 2002). Seurauksena ovat maidontuotantoon liittyvät ongelmat ja porsaiden lisääntynyt kuolleisuus (Algers ja de Passillé, 1991).

Olennaista hyvinvointitutkimuksessa on kunkin eläinlajin luontaisen käyttäytymisen tunteminen, sillä muutokset luontaisessa käyttäytymisessä ja käyttäytymishäiriöt kielivät hyvinvointiongelmista. Tyypillisiä esimerkkejä käyttäytymishäiriöistä, jotka aiheutuvat ensisijaisesti eläimen ongelmista sopeutua ympäristöönsä ovat lisääntynyt aggressiivisuus, sikojen hännänpurenta, kanojen höyhenten nokkiminen. Tuotantoeläimemme ovat laumaeläimiä, jotka luontaisesti elävät pysyvissä, suhteellisen pienissä ja usein lähisukulaisista koostuvissa ryhmissä. Ryhmien arvojärjestys ylläpidetään pienin elein, eikä tappeluita tarvita. Aggressiiviset yhteydenotot ovat kuitenkin tavallisia ongelmia tuotanto-oloissa. Syynä tähän voi olla väärän kokoinen ryhmä (Keeling ym, 2003), toisilleen vieraiden eläinten sekoittaminen $\left(\mathrm{O}^{\prime}\right.$ Connell ym, 2004) tai kilpailu ruuasta tai tilasta (Turner ym, 2000). Esimerkiksi lehmien väkirehukioski havaittiin aiheuttavan runsaasti lehmien välistä kiistaa, joka näkyy häirintänä ja eläinten ruokailun keskenjäämisenä (Helin ym, 2001, Katila ym, 2001).

Hännänpurenta sioilla on vakava ongelma, joka todennäköisesti johtuu liian korkeasta kroonisesta tai akuutista stressitasosta. Suomessa hännänpurentaa esiintyy ainakin noin $10 \%$ sioista (Valros ym, 2003). Hännänpurennan voi laukaista useat eri tekijät, mutta sille altistavat erityisesti virikkeettömät ja ahtaat olot (Häkkinen ym, 2003, Moinard ym, 2003). Kun sialla ei ole mahdollisuutta suunnata tonkimistarvettaan ympäristöön, turhautuminen puretaan helposti puremalla toisten sikojen häntiä (Beattie ym, 2000). Kanojen höyhenten nokkiminen ja kannibalismi ovat sikojen hännänpurentaan verrattavissa olevia ongelmia, joiden taustalta löytyy sekä ympäristötekijöitä että yksilökohtaisia eroja (Fraser \& Broom, 1997, Cheng ym, 2001).

\section{Käyttäytymistesteillä kysytään eläimen mielipidettä}

Eläinten tarpeiden huomioiminen on edellytys hyvälle eläintenpidolle. Käyttäytymistarpeiden tunnistaminen ja toteaminen sekä niiden tärkeyden todistaminen ovat oleellinen osa hyvinvointitutkimusta. Eläimen luontaisen käyttäytymisen tunteminen on tässäkin perusedellytys. On kokeellisesti mahdollista selvittää mitkä eläinten luontaisista käyttäytymismalleista ovat niille tärkeitä, ja kuinka tärkeitä. Valintakoe voi tuoda vastauksen kysymykseen mitä eläin haluaa ja välineellisellä ehdollistamisella (engl. operant conditioning) voidaan eläimeltä kysyä kuinka tärkeä tietty resurssi tai mahdollisuus toimintaan sille on.

Valintakokeilla on tutkittu muun muassa lypsylehmien makuualustapreferenssejä. Mannisen ym (2002) kokeissa selvitettiin, minkä alustan lehmä valitsee pihatto-olosuhteissa, kun tarjolla oli esim. oljella kuivitettu hiekka, betoni tai kumimattoparsi. Myös sikojen virikemieltymyksiä on selvitetty valintakokein antamalle niille mahdollisuus valita eri kuivikkeilla varustettujen karsinoiden välillä (Beattie ym, 1998). Välineellisen ehdollistamisen avulla on esimerkiksi pystytty osoittamaan, että sika on valmis tekemään enemmän työtä saadakseen käyttöönsä turvetta kun olkea (Pedersen ym, julkaisematon). Lehmällä on pystytty osoittamaan makaamisen tärkeys välineellisen ehdollistamisen menetelmällä (Munksgaard, julkaisematon). Lypsylehmät pitävät kiinni makaamismahdollisuudesta jopa syömisen tai sosiaalisen seuran kustannuksella (Munksgaard et al., 2003).

\section{Akuuttia ja kroonista stressiä tutkitaan monitieteellisin menetelmin}

Käyttäytyminen ei ole yksinään tarpeeksi luotettava mittari eläinten hyvinvoinnin objektiiviselle arviolle. Hyvinvointitutkimus onkin monitieteellinen ala, jossa käytetään laajaa kirjoa menetelmiä. Kokonaisvaltaisen kuvan saamiseksi tulee käyttäytymisen lisäksi seurata esimerkiksi eläinten hormonaalisia muutoksia, aineenvaihduntaa ja vastustuskykyä, sekä tietenkin terveyttä ja tuotosta. 
Akuutin stressin mittaaminen tapahtuu yleensä mittaamalla stressireaktioon liittyviä hormonaalisia ja fysiologisia muutoksia. Merkkejä akuutista stressistä ovat esim. kohonneet adrenaliini- ja kortisolitasot, nopeutunut pulssi sekä kohonnut ruumiinlämpö. Akuutin stressin merkkejä ovat myös eläinten käyttäytymisen muutokset, kuten levottomuus, ääntely, pelokkuus tai hyökkäävyys.

Kroonista stressiä aiheutuu jos eläin jatkuvasti joutuu elämään olosuhteissa, joihin se ei kykene sopeutumaan. Krooninen stressi on hankalasti mitattavissa, sillä jatkuva stressireaktio aiheuttaa elimistössä monimuotoisia muutoksia ja sopeutumista. Esimerkiksi kortisolin vuorokausirytmi lamaantuu tilanteessa, jossa ympäristö ei vastaa eläimen luontaisia tarpeita. Käytännön esimerkki tällaisesta tilanteesta on sikojen pitäminen virikkeettömissä oloissa, jolloin on havaittu, että kortisolitason vuorokausivaihtelu vähenee (De Jong ym, 2000). Krooninen stressireaktio kuluttaa jatkuvasti paljon energiaa, jolloin tuotantoon, kasvuun ja vastustuskykyyn jää vähemmän energiaa jää käytettäväksi (Toates, 1995).

Kroonisesti stressaantunut tai turhautunut eläin muuttaa myös käyttäytymistään. Stereotyyppiset, eli toistuvat, kaavamaiset käyttäytymiset ovat merkki, että eläimellä on tai on ollut hankaluuksia sopeutua ympäristöön. Näiden käyttäytymismallien avulla eläin pystyy todennäköisesti lisäämään hyvää oloaan hermovälittäjä-aineiden kautta (Fraser \& Broom, 1997). Stereotyyppiset käyttäytymismallit kehittyvät helposti tavaksi, josta on vaikea päästä eroon, vaikka niitä aiheuttanut alkuperäinen ongelma korjataankin. Normaalien käyttäytymismallien muutokset saattavat myös olla osoituksia ympäristön ongelmista, esimerkiksi sialla virikkeettömyys lisää inaktiivisuutta (Beattie, ym, 2000) ja naudalla makuuaika saattaa lyhentyä, jos lattiapinta on epämukava (Manninen, ym. 2002).

\section{Eläinten hyvinvoinnin tutkimuskeskus}

Suomessa kotieläinten käyttäytymis- ja hyvinvointitutkimus on pieni mutta aktiivinen tutkimusala, jolla on hyvät kansainväliset yhteydet. Osoitus tästä on, että kansainvälisen alan tutkijajärjestön (ISAE - International Society for Applied Ethology) vuosittaisen kongressin järjestelyvastuu on Suomella vuonna 2004 (www.isae2004.org). Lisätäksemme alan kansallista näkyvyyttä ja tehostaaksemme tutkimustoimintaamme perustimme Helsingin yliopistolle syksyllä 2003 Eläinten hyvinvoinnin tutkimuskeskuksen, jonka tavoitteena on edistää kotieläinten hyvinvointitiedettä ja käyttäytymisen tuntemusta. Tällä hetkellä keskuksella ei ole omaa budjettia.

Keskuksemme jäsenet käyttävät soveltavan etologian (käyttäytymistieteen) ja eläinten hyvinvointitieteen kansainvälisen tutkijayhteisön käyttämiä ajankohtaisia ja hyväksi todettuja tieteen menetelmiä. Keskuksemme poikkitieteellisen asiantuntijayhteisön jäsenet, eläinlääkärit, biologit ja agronomit, ovat ISAE - järjestön jäseniä. Hyvinvoinnin mittaamiseksi käytössämme on erilaisia menetelmiä; fysiologiset parametrit, käyttäytymismittarit, terveyteen, ruokintaan ja tuotantoympäristöön liittyvä tietous sekä epidemiologiset menetelmät. Yhteistyön kehittämiseksi Keskus pyrkii kokoamaan tutkimusyhteistyöhöön alaa lähellä olevat tutkimusryhmät Helsingin yliopistosta. Keskus toimii myös läheisessä yhteistyössä muiden suomalaisten eläinten hyvinvointia tutkivien ryhmien ja tutkijoiden kanssa.

Eläinten hyvinvoinnin tutkimuskeskus kouluttaa sekä eläinlääketetieteen opiskeljoita, että jo valmistuneita eläinlääkäreitä, jatko-opiskelijoita ja neuvojia. Lisäksi pyrimme tarjoamaan koulutusta myös muille kotieläinten kanssa työskenteleville tahoille. Varmistamme korkean koulutuksen tason tarvittaessa keskuksen ulkopuolisilla, kotimaisilla ja ulkomaisilla asiantuntijoilla. Keskus pyrkii tiedottamaan omasta ja maailmalla tapahtuvasta tutkimuksesta mahdollisimman tehokkaasti, sillä uskomme, että tieteentekijöiden on edistettävä saatujen tutkimustuloksten höydyntämistä käytännön työssä. Keskus ylläpitää eläinten käyttäytymiseen ja hyvinvointiin keskittyvää verkkosivustoa, josta löytyy tietoa keskuksen toiminnasta ja ajankohtaisista tapahtumista (www.vetmed.helsinki.fi/hyvinvointikeskus).

Tällä hetkellä keskuksen jäsenten tutkimushankkeet keskittyvät vasikoiden uneen ja hyvinvointiin, vasikoiden juottoon, lypsylehmien makuualustaan, emakoiden emo-ominaisuuksiin, lihasikojen hännänpurentaan ja virikkeiden vaikutukseen niiden hyvinvointiin sekä munivien kanojen hyvinvointiin. Keskuksessa toimii kaksi väitellyttä tutkijaa, kuusi jatko-opintoja suorittavaa tutkijaa ja muuttuva joukko syventävien opintojen sekä pro Gradu - tutkielma tekijöitä.

Vaikka kotieläinten käyttäytymis- ja hyvinvointitutkimus on suhteellisen nuori tieteenala, kasvaa se kuitenkin nopeasti yhteiskunnan tarpeiden ja toiveiden mukaan. Eläintenpitoon liittyy paljon tunteita ja mielipiteitä mutta ainoastaan tuottamalla tieteellisesti pätevää tietoa kotieläinten 
hyvinvoinnista voidaan varmistaa, että päätöksenteko ja käytännön ratkaisut sovelletaan eläinten hyvinvointia silmällä pitäen.

\section{Kirjallisuusluettelo:}

Algers, B. \& de Passillé, A.M.B., 1991, En ny syn på smågrisdödligheten. Svensk veterinärtidning 43: 659-663. Beattie, V.E., Walker, N. \& Sneddon, I.A. 1998. Preference testing of substrates by growing pigs. Animal Welfare 7: 27-34.

Beattie, V.E., O'Connell, N.E. \& Moss, B.W. 2000. Influence of environmental enrichment on the behaviour, performance and meat quality of domestic pigs. livest. Prod. Sci. 65: 71-79.

Cheng, H.W., Dillworth., G., Singleton, P., Chen, Y. \& Muir, W.M. 2001. Effects of group selection for productivity and longevity on blood concentrations of serotonin, cathecholamines and corticosterone of laying hens. Poultry Sci. 80: 1278-1285.

Damm, B. I., M. Bildsoe, C. Gilbert, J. Ladewig, and K. S. Vestergaard. 2002. The effects of confinement on periparturient behaviour and circulating prolactin, prostaglandin F-2 alpha and oxytocin in gilts with access to a variety of nest materials. Appl. Anim. Behav. Sci. 76:135-156.

De Jong, I. C., I. T. Prelle, J. A. Van de Burgwal, E. Lambooij, S. M. Korte, H. J. Blokhuis, \& J. M. Koolhaas. 2000. Effects of environmental enrichment on behavioral responses to novelty, learning, and memory, and the circadian rhythm in cortisol in growing pigs. Physiology \& Behavior 68: 571-578.

Fraser, A.F. \& Broom, D.M., 1997. Farm animal behaviour and welfare. CAB international. New York, USA.

Helin J., Katainen A., Manninen E., Norring M., Kaustell K. ja Saloniemi H. 2001 Väkirehuautomaatin käyttö lypsylehmillä pihattonavetassa Osa 1: Häirintä väkirehuautomaatilla, Suomen eläinlääkärilehti 107: $562-567$.

Herskin, M. S., K. H. Jensen, and K. Thodberg. 1998. Influence of environmental stimuli on maternal behaviour related to bonding, reactivity and crushing of piglets in domestic sows. Appl. Anim. Behav. Sci. 58:241-254

Häkkinen, Tanja, Anna Valros, Susanna Ahlström, Hannu Saloniemi, 2002. Hännänpurennan esiintyvyys yhdistelmä -ja lihasikaloissa sekä tilaolosuhteiden yhteys hännänpurentaan laatuluokkasikaloissa, Suomen Eläinlääkärilehti 3: 141-147.

Katila T., Katainen A., Kaustell K., Manninen E., Norring M., ja Saloniemi H. 2001. Väkirehuautomaatin käyttö lypsylehmillä pihattonavetassa Osa 2: Väkirehuautomaatilla tapahtuvan häirinnän suhde lehmän väkirehun saantiin ja maidontuotantoon, Suomen eläinlääkärilehti 107: 701-705.

Keeling, L.J., Estevez, I., Newberry, R.C. \& Correia, M.G. 2003. Production-related traits of layers reared in different sized flocks: the concept of problematic intermediate groups. Poultry Sci. 82: 1393-1296.

Manninen, E., de Passillé, A.M., Rushen, J., Norring, M. and Saloniemi, H. 2002: Preferences of dairy cows kept in unheated buildings foe different kind of cubicle flooring. Appl. Anim. Behav. Sci. 75: 281-292

Moinard, C., Mendl., M., Nicol, C.J., Green, L.E. 2003. A case control study of on-farm risk factors for tail biting in pigs. Appl. Anim. Behav. sci. 81: 333-355.

Munksgaard, L., Jensen, M.B., Pedersen, L.J., Hansen, S.W. \& Matthews, L. 2003. Effects of time constraints on resting, eating and social behaviour in dairy cows. ISAE Nordic winter symposium 23-25. 12003 , Sigtuna, Sweden, Abstraktikokoelma, s. 23.

O'Connell, N.E., Beattie, V.E. \& Moss, B.W. 2003. Influence of replacement rate on the welfare of sows introduced to a large dynamic group. Appl. Anim. behave. Sci. 85: 43-56.

Raussi, S., Lensink, B., Boissy, A., Pyykkönen, M., Veissier, I. 2003. The Effect of Contact with Conspecifics and Humans on Calves' Behaviour and stress responses. Animal Welfare 12: 191-203.

Thodberg, K., K. H. Jensen, M. S. Herskin, and E. Jorgensen. 1999. Influence of environmental stimuli on nest building and farrowing behaviour in domestic sows. Appl. Anim. Behav. Sci. 63:131-144.

Thodberg, K., K. H. Jensen, and M. S. Herskin. 2002. Nursing behaviour, postpartum activity and reactivity in sows - Effects of farrowing environment, previous experience and temperament. Appl. Anim. Behav. Sci. 77:53-76.

Toates, F. 1995. Stress - Conceptional and biological aspects. John Wiley \& Sons Ltd. Chichester, UK.

Turner, S.P., Ewen, M., Rooke, J.A. \& Edwards, S.A. 2000. the effect of space allowance on performance, aggression and immune competence of growing pigs housed on deep-litter at different group sizes. Livest. Prod. Sci. 66: 47-55.

Valros, A., Ahlström, S., Rintala, H., Häkkinen, T. and Saloniemi, H. 2003. Prevalence of tail biting in pigs and associations to carcass condemnations - a Finnish pilot study. ISAE 2004 - congress proceedings, p.108.

Wallgren, P. \& Lindahl, E. 1996. The influence of tail biting on performance of fattening pigs. Acta Vet. Scand. 37: 453-460. 